\title{
Effect of Modified Starches on Rheological Properties of Ketchup
}

\author{
Lesław Juszczak • Zbigniew Oczadły • \\ Dorota Gałkowska
}

Received: 2 October 2011 / Accepted: 20 February 2012/Published online: 4 March 2012

(C) The Author(s) 2012. This article is published with open access at Springerlink.com

\begin{abstract}
The aim of this work was to study the effect of commercial modified starches of different origin on rheological properties of ketchup. The following starches were used to produce the ketchup samples: chemically modified potato (acetylated distarch adipate from potato starch), waxy maize (acetylated distarch adipate from waxy maize starch and hydroxypropyl distarch phosphate from waxy maize starch), and cassava (acetylated distarch adipate from cassava starch) starches and physically modified cassava and waxy maize starches (physically modified cassava starch and physically modified waxy maize starch). The SEM microphotographs revealed that swollen or disrupted starch granules were present in the ketchup samples. As was evaluated by particle size distribution analysis, two peaks characteristic for different starch granule sizes were observed, the first peak at about $100 \mu \mathrm{m}$ for ketchup thickened with potato starch and the second one at about $50 \mu \mathrm{m}$ for the rest of the samples. Ketchups showed non-Newtonian, shearthinning flow with tendency to yield stress. Values of the rheological parameters describing the flow curves significantly correlated with Bostwick consistency. Ketchup samples exhibited different susceptibility for temperature changes, while values of flow activation energy were from 4.18 to $9.00 \mathrm{~kJ} / \mathrm{mol}$. On the basis of mechanical spectra, it is noted that values of $\mathrm{G}^{\prime}$ were higher than these of $\mathrm{G}^{\prime \prime}$
\end{abstract}

\footnotetext{
L. Juszczak $(\bowtie) \cdot$ D. Gałkowska

Department of Analysis and Evaluation of Food Quality,

University of Agriculture in Krakow,

Balicka 122 Street,

30-149 Krakow, Poland

e-mail: rrjuszcz@cyf-kr.edu.pl

Z. Oczadly

Ergo Solutions,

Borkowska 9 Street,

30-438 Krakow, Poland
}

showing that elastic properties dominated over the viscous ones. Ketchup samples exhibited properties of weak gels which were estimated from the values of $G^{\prime}$ and $G^{\prime \prime}$ moduli and their relation and from values of tangent of phase angle $(\tan \delta=0.14-0.37)$. Principal component analysis revealed both similarities and differences in rheological behavior of the examined ketchup samples thickened with different modified starches.

Keywords Ketchup · Modified starches · Consistency . Rheological properties

\section{Introduction}

Ketchup is a vegetable sauce produced from tomato concentrate and sugar, vinegar, salt, and different spices. Poland is the third largest market of consumption of ketchup in Europe, after Germany and Great Britain (Ochmańska 2006). Ketchup is a popular product that is used with different foods because it improves their taste. Moreover, it is easy to use and a low-calorie product. Ketchup is also a source of valuable carotenoids, of which the most abundant is lycopene.

From the physical point of view, ketchup is two-phase system in which solid particles of tomato pulp and added spices are dispersed in a colloidal continuous phase that consists of sugars, salts, organic acids, a fraction of soluble pectins, and other compounds of extract dissolved in water. Viscosity of the continuous phase is mostly affected by thickening substances, especially polysaccharide hydrocolloids used to produce a ketchup (Gujral et al. 2002; Sahin and Özdemir 2004; Koocheki et al. 2009). Ketchup is nonNetwonian, shear-thinning fluid, with yield stress. It also shows thixotropy and viscoelastic properties (Bottliglieri et 
al. 1991; Varela et al. 2003; Sahin and Özdemir 2004; Sharoba et al. 2005; Koocheki et al. 2009). Rheological properties of ketchup are essentially affected by the rheological characteristics of tomato concentrate (Bayod et al. 2008; Barbana and El-Omri 2009). The critical parameters that influence the rheological properties of tomato concentrate and ketchup are tomato variety, the sieve pore sizes, and temperature of the concentration process (Sànchez et al. 2002; Valencia et al. 2004). Bayod et al. (2008) stated that the volume fraction of solids is the most important parameter affecting rheological properties of tomato concentrate and ketchup. Rheological properties of ketchup depend not only on the amount of tomato paste used and its rheological characteristics but also on the kind and amount of added thickening substances. The most often used thickening agents are polysaccharide hydrocolloids such as: guar gum, xanthan, tragacanth, pectins, and sodium alginate (Gujral et al. 2002; Varela et al. 2003; Sahin and Özdemir 2004; Sahin and Özdemir 2007; Koocheki et al. 2009). These substances essentially improve sensory and rheological properties of ketchup. Guar and xanthan gums and their mixtures are found to be the most successful in decreasing serum separation of tomato ketchups (Varela et al. 2003; Sahin and Özdemir 2007). Other thickening substances used in production of ketchup are modified starches (Lee et al. 1997), soy protein (Thakur et al. 1996), dried tomato paste (Farahnaky et al. 2008), as well as oat hydrolyzates in mixture with polysaccharide hydrocolloids (Gibiński et al. 2006).

Starch is one of the most functional food components. However, in its native form it shows low rheological stability and low resistance to mechanical, thermal, and chemical agents. Moreover, it undergoes retrogradation and syneresis phenomena that limit the use of native starch in many food products. In order to improve some physicochemical properties of the native starch, it can be modified by chemical, physical, and/or enzymatic methods or their combinations. The resulting starch preparations exhibit different functional properties and are used as gelling, thickening, stabilizing, and filling agents in food production (Lee et al. 1997, Tharanathan 2005, Gibiński et al. 2006, Galanakis et al. 2010).

The aim of this work was to evaluate the effect of commercial modified starches of different origin on the rheological properties of ketchup. In order to find out how the kind of modification and a botanical source of starch affect the rheological properties of ketchup, several modified starches were used in this study. Considering the fact that use of chemically modified starch in food products raises consumers' concerns in this study, physically modified starches that do not have status of food additives were also used.

\section{Materials and Methods}

Materials

Ketchup was produced in the plant laboratory by mixing the following basic components: tomato paste, vinegar, salt, sucrose, and spices, according to a proprietary recipe. Benzoic acid was used as a preservative. At the final stage of ketchup production, a water starch suspension was added to the semifinished product; then it was mixed and heated to $80{ }^{\circ} \mathrm{C}$. After cooling the ketchup, samples were packed to the commercial containers and then stored under refrigeration up to the analyses. The resulted products contained $26-27 \%$ of dry mass and extract content was about $30{ }^{\circ} \mathrm{Bx}$. All of samples contained $3 \%(w / w)$ of modified starch. The following commercial preparations of modified starches were used: acetylated distarch adipate from potato starch (ADA-PS), acetylated distarch adipate from waxy maize starch (ADA-WMS), acetylated distarch adipate from cassava starch (ADA-CS), hydroxypropyl distarch phosphate from waxy maize starch (HDP-WMS), physically modified cassava starch (PM-CS), and physically modified waxy maize starch (PM-WMS). All the starches were obtained from one producer and were not additionally modified in any way before use.

\section{Methods}

\section{SEM Microscopy and Particle Size Distribution}

SEM microphotographs were taken using scanning electron microscope Nova Nano SEM 200 (FEI, Hillsboro, USA). Before analysis, $5 \mathrm{~g}$ of ketchup sample was mixed with 30 $\mathrm{ml}$ of deionized water and centrifuged (at 8,000 rpm); the supernatant was discarded and the remaining precipitate was rinsed with deionized water and centrifuged again at 8,000 $\mathrm{rpm}$. Part of the resulting precipitate was transferred to the microscope holder and dried in an oven dryer (BMT, Brno, Czech Republic) with forced air at $35{ }^{\circ} \mathrm{C}$, and then was vacuum-coated with a thin layer of carbon as a conducting material.

Particle size distributions were measured using a Malvern Mastersizer 2000 laser diffraction particle size analyzer (Malvern Instruments Ltd, Worcestershire, UK). The measurement parameters were as follows: particle refractive index $\mathrm{RI}=1.520$ and absorption 0.1 .

\section{Rheological Properties}

The consistency of ketchup was measured using a Bostwick consistometer (CSC Scientific Company, Inc, Fairfax, USA) according to recommendations of ASTM Standard (ASTM International, 2002). Ketchup sample in the amount for 
filling the reservoir was loaded into the compartment of consistometer and the measurement was performed at room temperature. The gate was opened and the distance traveled by the leading edge of the sample after $30 \mathrm{~s}$ was recorded.

Flow curve tests were carried out on the ketchup samples using a rotational rheometer Rheolab MC1 (Paar Physica $\mathrm{GmbH}$, Ostfildern, Germany) with cup and bob measurement system (diameter 27.12/25.00 mm) controlled by US 200 software (Paar Physica GmbH, Ostfildern, Germany). Before measurement, the sample was relaxed and thermostated at the given measurement temperature within $5 \mathrm{~min}$. The sample was subjected to a programmed increasing and decreasing shear rate in the range of $1-500 \mathrm{~s}^{-1}$ within 10 min at temperatures ranged from 10 to $60{ }^{\circ} \mathrm{C}$, with $10{ }^{\circ} \mathrm{C}$ interval. The temperature was controlled with a temperature circulator Viscotherm VT2 (Paar Physica, GmbH, Ostfildern, Germany).

Flow behavior was described by fitting Herschel-Bulkley (1) and the power law (2) rheological models to shear stressshear rate experimental data (Sharoba et al. 2005).

$\tau=\tau_{0}+K \cdot \dot{\gamma}^{n}$

$\tau=K \cdot \dot{\gamma}^{n}$

where $\tau$ is shear stress (in pascals), $\dot{\gamma}$ is shear rate (in per second), $\tau_{0}$ is yield stress (in pascals), $K$ is consistency coefficient (in pascals per second ${ }^{n}$ ), and $n$ is flow behavior index.

The time dependency of shear stress at constant shear rate of $100 \mathrm{~s}^{-1}$ was evaluated in range of $0-300 \mathrm{~s}$ at temperature of $20{ }^{\circ} \mathrm{C}$. The experimental data were fitted to Weltman Eq. (3) (Choi and Yoo 2004; Juszczak et al. 2004):

$\tau=A-B(\ln t)$

where $\tau$ is shear stress (in pascals), $t$ is time of shearing (in seconds), $A$ and $B$ are constants: $A$-instantaneous stress needed for initiating the structure breakdown process during shearing (in pascals), $B$-time coefficient of thixotropic breakdown (Basu et al. 2007).

The effect of temperature in range of $10-60{ }^{\circ} \mathrm{C}$ on the consistency coefficients was described by Arrhenius Eq. (4) (Juszczak et al. 2004; Sharoba et al. 2005):

$K=K_{\infty} \cdot \exp \cdot\left(\frac{E_{\mathrm{a}}}{R \cdot T}\right)$

where $K$ is the consistency coefficient at measurement temperature (in pascals per second ${ }^{n}$ ), $K_{\infty}$ is a constant (in pascals per second ${ }^{n}$ ), $E_{\mathrm{a}}$ is the flow activation energy (in joules per mole), $R$ is the universal gas constant (in joules per mole per Kelvin), $T$ is the absolute temperature (in Kelvin).
Viscoelastic properties of ketchup samples were evaluated using MARS II rheometer (Thermo Scientific, Karlsruhe, Germany) with cone/plate system (diameter, $60 \mathrm{~mm}$; angle, $1^{\circ}$; gap, $0.052 \mathrm{~mm}$ ). Before measurement, the ketchup sample was loaded in the measuring element and allowed to stabilize at the desired temperature and relax within $5 \mathrm{~min}$. Mechanical spectra of ketchup at $20{ }^{\circ} \mathrm{C}$ were determined in the linear viscoelastic range at constant strain 0.005 in a range of frequency of $1-100 \mathrm{rad} / \mathrm{s}$. The temperature was controlled with a temperature circulator Phoenix II (Thermo Scientific, Karlsruhe, Germany). Values of storage $\left(G^{\prime}\right)$ and loss $\left(G^{\prime \prime}\right)$ moduli were recorded and the mechanical spectra were described by power law Eqs. (5 and 6) (Juszczak et al. 2004; Sharoba et al. 2005):

$G^{\prime}=K^{\prime} \cdot \omega^{n^{\prime}}$

$G^{\prime \prime}=K^{\prime \prime} \cdot \omega^{n^{\prime \prime}}$

where $G^{\prime}$ is storage modulus (in pascals), $G^{\prime \prime}$ is loss modulus (in pascals), $\omega$ is angular frequency (in radians per second), and $K^{\prime}, K^{\prime \prime}, n^{\prime}$, and $n^{\prime \prime}$ are experimentally determined constants.

Statistical Analysis

In order to estimate the significance of differences between means, a one-way analysis of variance was conducted and values of the least significance difference was calculated at the level of significance 0.05 using Fisher's test. Pearson correlation coefficients between selected rheological parameters were also determined at the level of significance set at 0.05 . Additionally, principal component analysis (PCA) was used to provide a ready means of visualizing the differences and similarities among the ketchup samples. Calculations were made using Statistica v. 9.0 software (StatSoft, Tulsa, OK, USA).

\section{Results and Discussion}

Scanning Electron Microscopy and Particle Size Distribution

A characteristic feature of a suspension is presence of solid particles dispersed in the continuous phase. Size and shape of these particles are major factors that contribute to the rheological properties of such systems. In the case of ketchup, suspended solid particles come from cell wall fragments of tomato fruits. The size of the particles in ketchup depends on the pore sizes of the sieve used during tomato paste processing (Bayod et al. 2008). Other factors that affect the particle size distribution of tomato pulp are temperature 
of processing and homogenization. According to Bayod et al. (2008), homogenization of ketchup components drastically reduces the size of large particles. Starch preparations used in ketchup processing in order to enhance viscosity also affect the particle size distribution of ketchup because the starch is not completely gelatinized at pasteurization temperature. Thus, ketchup structure consists of both cell wall fragments coming from tomato fruit and swollen starch granules and partially degraded starch granules (Fig. 1).

Examples of particle size distribution of ketchups thickened with modified starches are shown in Fig. 2. In ketchup sample with ADA-CS, two main peaks: one at about $50 \mu \mathrm{m}$ and the other at about $300-400 \mu \mathrm{m}$, and one small peak at 2-3 $\mu \mathrm{m}$ were observed. A bimodal size distribution of both pastes and ketchups without added starches was observed by Bayod et al. (2008); however, they did not find particles of about $50 \mu \mathrm{m}$. Therefore, it can be suggested that the peak at $50 \mu \mathrm{m}$ observed in the present study comes from starch granules, while particles greater than $200 \mu \mathrm{m}$ are composed of tomato raw material. Ketchup samples with ADA-WMS, PMWMS, and HDP-WMS gave similar to ADA-CS particle size distributions. This resulted from the fact that waxy maize starch and cassava starch have similar granule size fractions. In the case of ketchup with ADA-PS, quite different particle size distribution was obtained (Fig. 2). A peak at $50 \mu \mathrm{m}$ did not appear, whereas a main peak at about $100 \mu \mathrm{m}$ was observed. This finding results from the nature of potato starch which is mainly composed of large granules that swell and increase their diameter easily at low temperatures.

\section{Bostwick Consistency}

The fundamental method used to determine consistency of ketchup and commonly used in quality assessment is measurement of flow length (in centimeter) of ketchup sample within a given time (the most often $30 \mathrm{~s}$ ) using the Bostwick consistometer. Results of the Bostwick measurement for ketchup samples are given in Fig. 3. Addition of starch preparations to the ketchups affected the consistency of the samples. The least flowable consistency was observed for sample with HDP-WMS, whereas the most fluid sample was that with ADA-PS starch. Because the ketchups contained the same amounts of tomato paste and were characterized by similar extract contents, probably the main factor affecting their consistency was presence of starch granules and their fragments originating from the starches used as thickening agents. In the available literature, the following values of Bostwick consistency are presented: 4.0-7.0 cm (Porretta 1991), 3.4-8.5 cm
Fig. 1 Scanning electron microphotographs of ketchup samples thickened with ADA-PS $(\mathbf{a}, \mathbf{b})$ and ADA-CS (c, d) starches
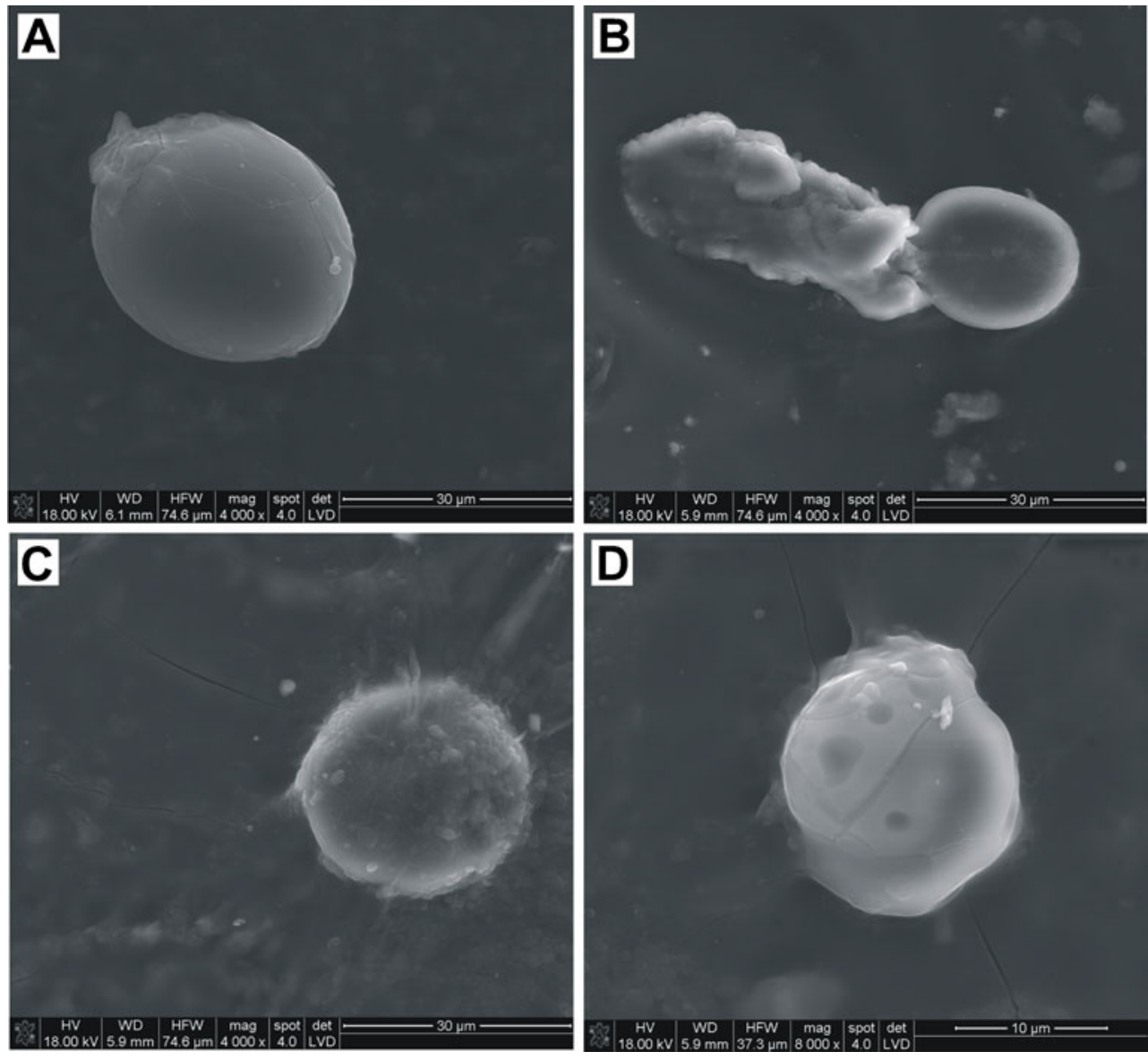

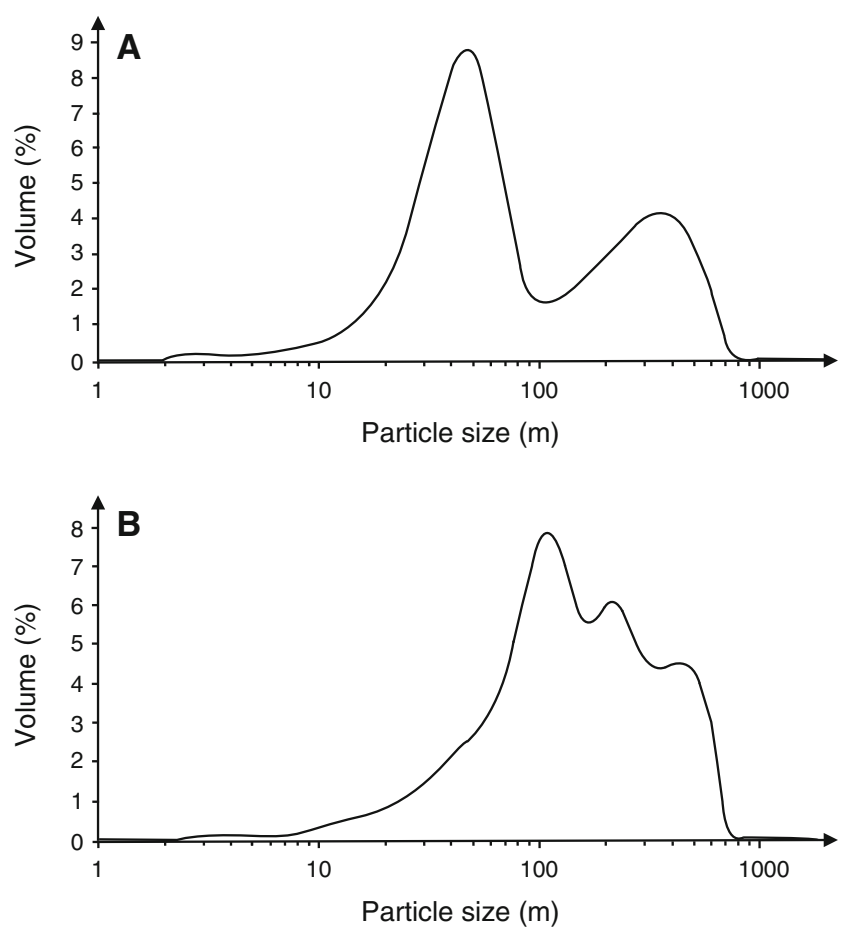

Fig. 2 Particle size distribution of ketchup samples thickened with ADA-CS (a) and ADA-PS (b) starches

(Bottliglieri et al. 1991), and 1.3-7.2 cm (McCarthy et al. 2008). Comparing the results of the present study with the literature data, it can be stated that consistency values of the ketchups thickened with starch preparations are in a range of consistency values reported by the cited authors. According to Mazaheri Tehrani and Ghandi (2007), values of Bostwick consistency of the tomato products are essentially determined by measuring temperature and extract content in the product.

Flow Behavior

Examples of flow curves of ketchups with modified starches determined at $20^{\circ} \mathrm{C}$ are shown in Fig. 4. The shape of these

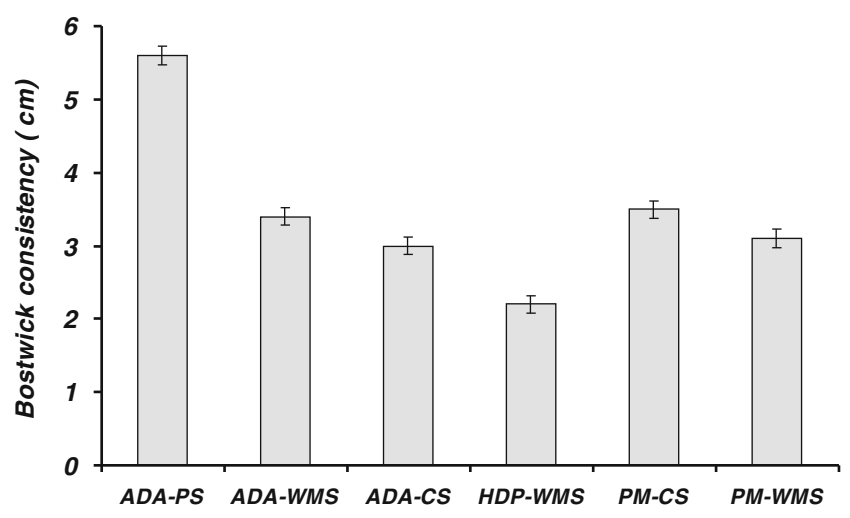

Fig. 3 Bostwick consistency of ketchup samples thickened with modified starches

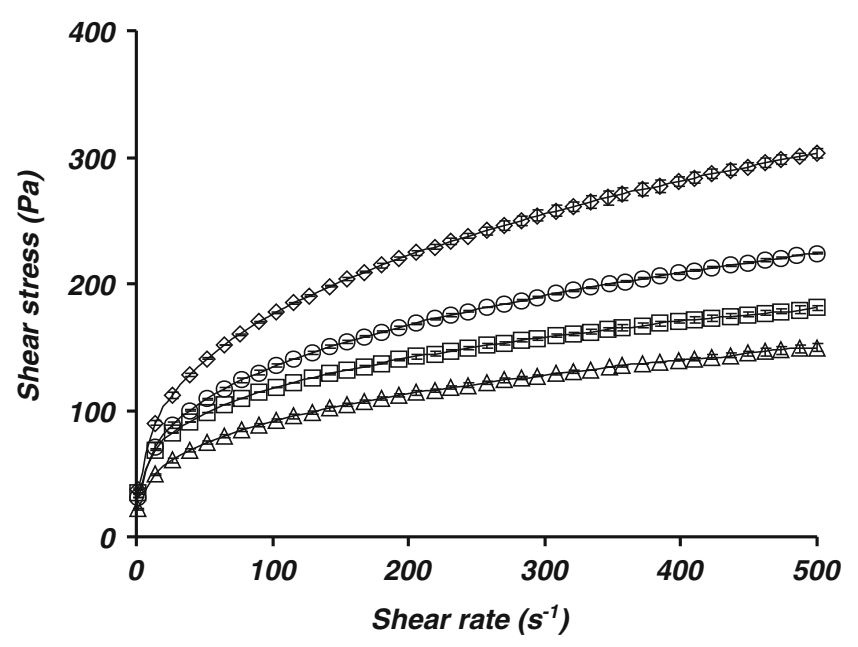

Fig. 4 Flow curves of selected ketchup samples thickened with modified starches: triangle ADA-PS, circle ADA-WMS, diamond HDPWMS, and square ADA-CS

curves shows non-Newtonian, shear-thinning flow with tendency to yield stress. Non-Newtonian flow behavior of ketchups was also observed by many authors (Bottliglieri et al. 1991; Lee et al. 1997; Gujral et al. 2002; Alvarez et al. 2004; Sahin and Özdemir 2004; Sharoba et al. 2005; McCarthy et al. 2008; Koocheki et al. 2009). The highest values of shear stress were showed by ketchup samples with HDP-WMS starch, whereas the lowest ones were stated for samples with ADA-PS. These results correlate with values of consistency, indicating that ketchup thickened with ADAPS showed the longest flow length (was the thinnest), whereas this with HDP-WMS exhibited one of the shortest length flow (was the thickest). Shear-thinning behavior, i.e., decrease in viscosity with increasing shear rate is a common phenomenon. In the case of ketchup, i.e., a product that has the structure of a suspension, shear-thinning phenomena results from orientation of solid particles of the tomato paste along the flow lines. The other factor influencing the viscosity of ketchup is presence of swollen and partially gelatinized starch granules or their fragments. At higher shear rates, individual starch granules can be deformed.

Values of rheological models' parameters used to describe the experimental flow curves are summarized in Table 1. Values of determination coefficients $\left(R^{2}\right)$ show that the Herschel-Bulkley model was better fitted to the flow curves. Values of yield stress of the ketchup samples ranged from 10.61 to $58.20 \mathrm{~Pa}$, with the lowest value observed for ketchup with ADA-PS starch. Values of yield stress significantly depend on quantitative and qualitative addition of thickening substance. Koocheki et al. (2009) observed that values of yield stress increased with increasing hydrocolloid concentration and decreased with increasing temperature. Lee et al. (1997) stated that acetylated distarch adipate 
Table 1 Parameters of rheological models describing flow of ketchup samples thickened with modified starches

\begin{tabular}{|c|c|c|c|c|c|c|c|}
\hline Sample & $\tau_{0 \mathrm{HB}}[\mathrm{Pa}]$ & $\mathrm{K}_{\mathrm{HB}}\left[\mathrm{Pa} \mathrm{s}^{n}\right]$ & $n_{\mathrm{HB}}$ & $R^{2}$ & $K\left[\mathrm{~Pa} \mathrm{~s}^{n}\right]$ & $n$ & $R^{2}$ \\
\hline ADA-PS & $10.61 \pm 0.67$ & $13.73 \pm 0.93$ & $0.38 \pm 0.01$ & 0.9975 & $21.80 \pm 0.49$ & $0.31 \pm 0.01$ & 0.9933 \\
\hline ADA-WMS & $19.69 \pm 0.54$ & $16.31 \pm 0.63$ & $0.42 \pm 0.01 \mathrm{a}$ & 0.9918 & $30.69 \pm 0.45$ & $0.32 \pm 0.00 \mathrm{a}$ & 0.9927 \\
\hline ADA-CS & $48.68 \pm 0.60$ & $3.13 \pm 0.02$ & $0.62 \pm 0.00$ & 0.9992 & $33.76 \pm 0.62 \mathrm{a}$ & $0.27 \pm 0.01$ & 0.9578 \\
\hline HDP-WMS & $58.20 \pm 0.80$ & $4.31 \pm 0.12$ & $0.68 \pm 0.00$ & 0.9915 & $36.67 \pm 0.09$ & $0.34 \pm 0.01$ & 0.9669 \\
\hline PM-CS & $33.11 \pm 2.45 \mathrm{a}$ & $9.44 \pm 0.24$ & $0.42 \pm 0.01 \mathrm{a}$ & 0.9989 & $34.27 \pm 1.55 \mathrm{a}$ & $0.24 \pm 0.01$ & 0.9873 \\
\hline PM-WMS & $33.10 \pm 1.36 \mathrm{a}$ & $6.49 \pm 0.19$ & $0.54 \pm 0.00$ & 0.9902 & $28.07 \pm 0.83$ & $0.32 \pm 0.01 \mathrm{a}$ & 0.9793 \\
\hline
\end{tabular}

Mean values of two repetitions \pm standard deviation. Mean values marked with the same letter in the column do not significantly differ at significance level of 0.05

increased the yield stress the most of different modified starches. Values of Herschel-Bulkley consistency coefficient ranged from 3.13 and $16.31 \mathrm{~Pa} \cdot \mathrm{s}^{n}$, whereas values of flow index were $0.38-0.68$. A significant broad range of values of consistency coefficient for ketchups thickened with modified starches are given by Lee et al. (1997). The cited authors observed also that values of the consistency coefficient increased with starch concentration, and the highest values of that parameter was found for sample thickened with acetylated distarch adipate present in concentration of more than $3 \%$. In this study, ketchups produced with acetylated starch and hydroxypropyl distarch phosphate showed lower values of $K$ parameter, whereas their values of flow index did not depend on the concentration of added modified starch (Table 1). A significant narrow range of values of Herschel-Bulkley consistency coefficient was reported by Koocheki et al. (2009) for ketchups thickened with hydrocolloids. The highest values of yield stress were observed for ketchups with HDP-WMS and ADA-CS starches (Table 1). These samples showed also relatively low values of consistency coefficient. The ketchup sample thickened with ADA-PS starch was characterized by low yield stress and intermediate value of consistency coefficient. The differences between the analyzed ketchup samples could result from different botanical origin of the starch preparations. At lower temperature, potato starch granules swell and gelatinize more easily than those of cereal starches. From a consumer perspective, low values of yield stress characterize product that is highly deliquescent and can flow off the dish, and hence it could not be accepted by consumer. Values of power law flow index and proved non-Newtonian flow and shear-thinning behavior of the ketchup samples were shown in Table 1. The lowest value of consistency coefficient was observed for ADA-PS sample and this finding correlates well with the value of Bostwick consistency and low yield stress determined for that ketchup sample. Values of power law consistency coefficient and flow index determined for ketchup samples fall in the wide ranges of these parameters reported in literature (Bottliglieri et al. 1991; Sahin and Özdemir 2004; McCarthy et al. 2008; Koocheki et al. 2009). Despite the fact that there are different physical bases of the measurements of consistency and fluid flow using Bostwick consistometer and rheometer, respectively, a negative correlation $(r=-0.88)$ between Bostwick consistency and power law consistency coefficient was observed. In the case of the Herschel-Bulkley parameters, the values of Bostwick consistency negatively correlated with yield stress $(r=-0.86)$ and flow index $(r=-0.79)$. A correlation between Bostwick consistency and rheological parameters was also reported by McCarthy et al. (2008).

\section{Time-Dependent Behavior}

Similar to other suspensions, ketchups belong to rheologically unstable fluids, whose properties depend on time of shearing. Determination of curves of shear stress (or apparent viscosity) as a function of time at constant shear rate allows characterization of that kind of fluid (Choi and Yoo 2004). The ketchup examined showed different flow behavior at constant shearing (Fig. 5). The ADA-PS sample was

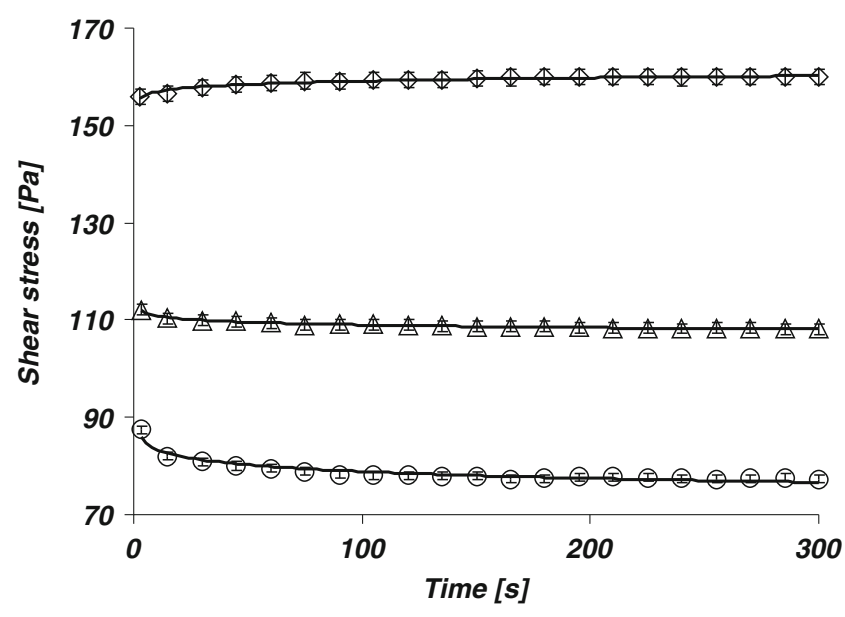

Fig. 5 Time-dependent flow behavior of selected ketchup samples thickened with modified starches: circle ADA-PS, triangle ADA-CS, and diamond HDP-WMS 
characterized by significant decrease in shear stress with increasing time that reflected its thixotropic properties. Ketchup with HDP-WMS showed little increase in viscosity during constant shearing. In literature, there are a few models proposed to describe shear stress or apparent viscosity dependence on time. According to Choi and Yoo (2004), such curves are well described by Weltman equation. Parameters of the Weltman model determined for analyzed ketchup samples are given in Table 2. The lowest value of initial shear stress was stated for ADA-PS sample but the highest for HDP-WMS. Values of $A$ parameter correlate positively with consistency coefficient of the power law model $(r=0.64)$ but negatively with Bostwick consistency $(r=-0.73)$. Choi and Yoo (2004) observed that values of $A$ parameter increased with increasing shear rate and decreased with increasing temperature. In opposition, values of $B$ parameter increased when temperature of measurement increased. Negative values of $B$ parameter suggest that shear stress (or apparent viscosity) decreases with shearing time, therefore they reflect the thixotropy phenomenon. The higher is the absolute value of the $B$ parameter; the more rheologically unstable the sample is. In the case of HDP-WMS and PM-WMS samples, the values of $B$ were positive that indicates that shear stress increases with shearing time, which is characteristic for antithixotropy phenomenon. However, flow curves of these samples determined at increasing and decreasing shear rates (curves not shown) intersected, indicating that the rheological instability of HDP-WMS and PM-WMS samples depended on shear rate. At low values of shear stress, the downward curves were positioned above the upward curves. As a result, positive values of B parameter of the Weltman model for $100 \mathrm{~s}^{-1}$ were obtained. At the highest values of shear stress, the upward and downward curves ran in the opposite direction to the above. Values of coefficient of thixotropic structure breakdown correlated positively with yield stress $(r=0.80)$ and the Herschel-Bulkley index $(r=0.87)$ but negatively correlated with Bostwick consistency

Table 2 Rheological parameters of Weltman model for ketchup samples thickened with modified starches

\begin{tabular}{lrrr}
\hline Sample & \multicolumn{1}{l}{$A[\mathrm{~Pa}]$} & \multicolumn{1}{l}{$B$} & $R^{2}$ \\
\hline ADA-PS & $88.08 \pm 0.97$ & $-2.00 \pm 0.07 \mathrm{a}$ & 0.9244 \\
ADA-WMS & $143.56 \pm 0.04$ & $-1.89 \pm 0.01 \mathrm{a}$ & 0.9743 \\
ADA-CS & $112.79 \pm 0.25$ & $-0.83 \pm 0.06$ & 0.9678 \\
HDP-WMS & $154.64 \pm 0.76$ & $0.98 \pm 0.11$ & 0.9455 \\
PM-CS & $102.07 \pm 0.04$ & $-1.58 \pm 0.01$ & 0.9710 \\
PM-WMS & $109.27 \pm 0.62$ & $0.25 \pm 0.03$ & 0.9525 \\
\hline
\end{tabular}

Mean values of two repetitions \pm standard deviation. Mean values marked with the same letter in the column do not significantly differ at significance level of 0.05 $(r=-0.74)$ and Herschel-Bulkley consistency coefficient $(r=-0.77)$.

Effect of Temperature on Flow Behavior

Temperature significantly influences viscosity of fluids. When temperature increases, energy is supplied to the sample, hence intermolecular interactions and internal friction during flow reduce, therefore viscosity of the system decreases (Sharoba et al. 2005). In the case of nonNewtonian fluids, the effect of temperature on their rheological properties is reflected in values of consistency coefficient or apparent viscosity at a given shear rate. Examples of curves of consistency coefficient $(K)$ in a function of temperature at range of $10-60{ }^{\circ} \mathrm{C}$ for ketchups with added modified starches are given in Fig. 6. The highest values of consistency coefficient were observed for HDP-WMS sample, whereas the lowest ones for ADA-PS sample. Values of consistency coefficient for ketchup samples ranged from 2.27 to $42.80 \mathrm{~Pa} \cdot \mathrm{s}^{n}$ at $10{ }^{\circ} \mathrm{C}$ and from 18.33 to $26.07 \mathrm{~Pa} \cdot \mathrm{s}^{n}$ at $60{ }^{\circ} \mathrm{C}$. A significant effect of temperature on consistency coefficient or apparent viscosity has been already reported in literature (Bottliglieri et al. 1991; Alvarez et al. 2004; Sharoba et al. 2005; Koocheki et al. 2009). Flow activation energy $\left(E_{\mathrm{a}}\right)$ is a parameter that describes the effect of temperature on viscosity of the system. Flow activation energy is a measure of changes in viscosity with increasing temperature and for Newtonian fluids ranges from $14.4 \mathrm{~kJ} / \mathrm{mol}$ for water to more than $60 \mathrm{~kJ} / \mathrm{mol}$ for sugar solutions and concentrated juices. Non-Newtonian fluids, including ketchups, have much lower values of flow activation energy (Krokida et al. 2001). Values of the parameters of Arrhenius equation for ketchup samples are summarized in Table 3 . The lowest flow activation energy was

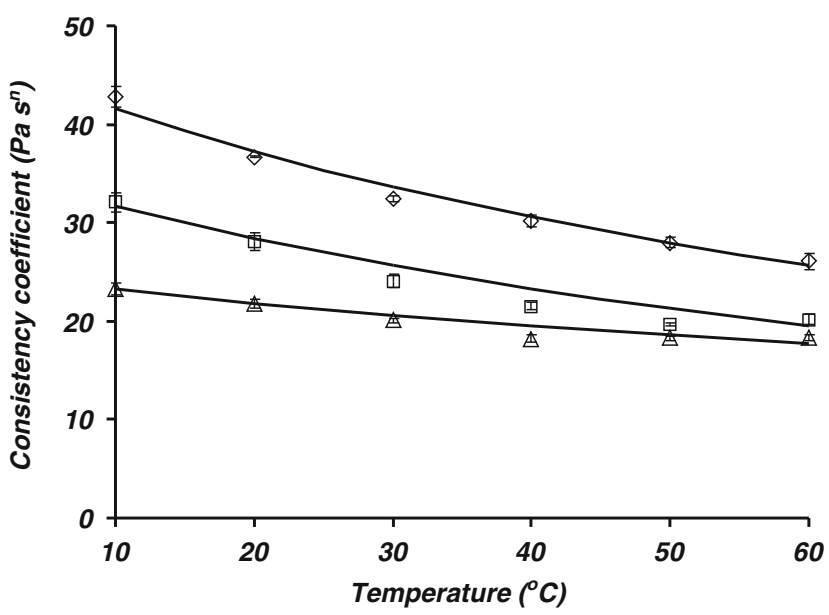

Fig. 6 Effect of temperature on values of consistency coefficient for selected ketchup samples thickened with modified starches: triangle ADA-PS, diamond HDP-WMS, square PM-WMS, and line model 
Table 3 Parameters of Arrhenius model describing dependence of consistency coefficient on temperature for ketchup samples thickened with modified starches

\begin{tabular}{llll}
\hline Sample & $K_{\infty}\left[\mathrm{Pa} \mathrm{s}^{n}\right]$ & $E_{\mathrm{a}}[\mathrm{kJ} / \mathrm{mol}]$ & $R^{2}$ \\
\hline ADA-PS & $3.87 \pm 0.13$ & $4.18 \pm 0.13$ & 0.9117 \\
ADA-WMS & $2.43 \pm 0.85 \mathrm{a}$ & $6.31 \pm 0.90 \mathrm{a}$ & 0.9556 \\
ADA-CS & $2.23 \pm 0.60 \mathrm{ab}$ & $6.67 \pm 0.68 \mathrm{a}$ & 0.9851 \\
HDP-WMS & $1.66 \pm 0.18 \mathrm{ac}$ & $7.58 \pm 0.23 \mathrm{a}$ & 0.9797 \\
PM-CS & $1.37 \pm 0.05 \mathrm{ad}$ & $9.00 \pm 0.62$ & 0.9905 \\
PM-WMS & $1.28 \pm 0.18 \mathrm{bcd}$ & $7.55 \pm 0.34 \mathrm{a}$ & 0.9116 \\
\hline
\end{tabular}

Mean values of two repetitions \pm standard deviation. Mean values marked with the same letter in the column do not significantly differ at significance level of 0.05

observed for ADA-PS sample, whereas the highest one for PM-CS sample. Values of the material constant $\left(K_{\infty}\right)$ differed little from each other. Sharoba et al. (2005) reported a narrower range of values of flow activation energy at temperatures from 0 to $50{ }^{\circ} \mathrm{C}$ for commercial ketchups. Moreover, they observed that values of $E_{\mathrm{a}}$ depended on sample composition and increased with increasing extract content. To the contrary, wider ranges of values of flow activation energy for commercial ketchups were given by Bottliglieri et al. (1991). Koocheki et al. (2009) observed that ketchups thickened with non-starch hydrocolloids showed significantly lower values of flow activation energy as compared to the control sample. The range of $E_{\text {a }}$ reported by the above authors was also much wider than that reported in this study. The differences in values of flow activation energy result from many factors connected with sample composition, as well as from different measurement temperatures. In this study, a negative correlation between values of flow activation energy and Bostwick consistency $(r=-0.72)$ and a positive one between flow activation energy and power law consistency coefficient $(r=-0.77)$ were found.

\section{Viscoelastic Properties}

Examples of mechanical spectra of ketchups with modified starches are shown in Fig. 7. At examined angular frequency range the values of storage modulus $\left(G^{\prime}\right)$ were higher than these of loss modulus $\left(G^{\prime \prime}\right)$, indicating that elastic properties of samples dominated the viscous ones. The highest values of $G^{\prime}$ and $G^{\prime \prime}$ were observed respectively for HDP-WMS and ADA-CS samples. Relatively low values of moduli and $\tan \delta=G^{\prime \prime} / G^{\prime}$ ranging between 0.14 and 0.37 indicated that the ketchup samples behaved as weak gels. Ketchup thickened with ADA-PS starch formed the weakest gel that is in accordance with its low values of yield stress and power law consistency coefficient. Sharoba et al. (2005) reported slightly

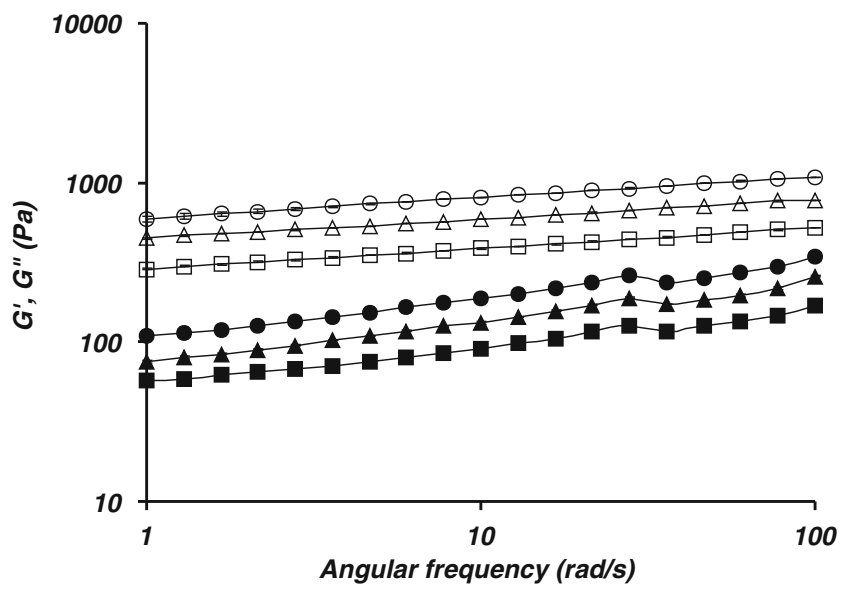

Fig. 7 Mechanical spectra of selected ketchup samples thickened with modified starches. $G^{\prime}$-empty markers, $G^{\prime \prime}$ - filled markers: square ADA-WMS, circle ADA-CS, and triangle PM-CS

narrower range of values of phase angle of commercial ketchups. Valencia et al. (2002) found that starch added to a tomato sauce as thickening agent affected the viscoelastic properties of the product. In order to describe the mechanical spectra, i.e., dependence of $G^{\prime}$ and $G^{\prime \prime}$ moduli on angular frequency, the power law models are used. The parameters of the equations describing the mechanical spectra of ketchup samples are summarized in Table 4. Values of $K^{\prime}$ parameter ranged from 287.69 $\mathrm{Pa}$ for ADA-WMS sample to 691.93 $\mathrm{Pa}$ for HDP-WMS sample. For the sample HDP-WMS, the $K^{\prime}$ parameter correlates well with high value of yield stress, power law consistency coefficient, and $A$ parameter of the Weltman equation. Variation of values of the $n^{\prime}$ parameter was much smaller than that of $K^{\prime}$ parameter. The highest value of $n^{\prime}$ was for the sample with ADA-PS starch. This indicates that ADA-PS sample was the most susceptible to the supplied stress. A narrow range of values of $K^{\prime}$ and a similar range of values of the $n^{\prime}$ parameter compared to those in this study were reported by Sharoba et al. (2005) for commercial ketchups. Values of $K^{\prime \prime}$ parameter ranged from 54.68 to $107.66 \mathrm{~Pa}$, whereas values of $n^{\prime \prime}$ were $0.22-0.27$. Slightly narrower ranges of values of these parameters were given by Sharoba et al. (2005). Positive correlations between $K^{\prime}$ and $K^{\prime \prime}$ parameters and yield stress ( $r=0.94$ and $r=0.77$, respectively), as well as between these parameters and Herschel-Bulkley flow index ( $r=0.88$ and $\mathrm{r}=0.77$, respectively) were found. On the other hand, $K^{\prime}$ and $K^{\prime \prime}$ parameters negatively correlated with Herschel-Bulkley consistency coefficient $(r=-0.85$ and $r=-0.88$, respectively).

\section{Principal Component Analysis}

The principal component analysis allows reduction of the number of variables using correlations between the variables 
Table 4 Parameters of power law models describing viscoelastic properties of ketchup samples thickened with modified starches

\begin{tabular}{llllcl}
\hline Sample & $K^{\prime}$ & $n^{\prime}$ & $R^{2}$ & $K^{\prime \prime}$ & $n^{\prime \prime}$ \\
\hline ADA-PS & $324.97 \pm 2.66$ & $0.15 \pm 0.01$ & 0.9994 & $72.56 \pm 0.16 \mathrm{a}$ & $0.24 \pm 0.01 \mathrm{a}$ \\
ADA-WMS & $287.69 \pm 2.85$ & $0.13 \pm 0.00 \mathrm{a}$ & 0.9995 & $54.68 \pm 0.24$ & 0.9885 \\
ADA-CS & $597.96 \pm 5.54$ & $0.14 \pm 0.00$ & 0.9985 & $107.66 \pm 1.45$ & $0.23 \pm 0.00$ \\
HDP-WMS & $691.93 \pm 15.22$ & $0.10 \pm 0.01$ & 0.9959 & $92.17 \pm 2.75$ & $0.24 \pm 0.00 \mathrm{a}$ \\
PM-CS & $447.26 \pm 2.58$ & $0.12 \pm 0.00$ & 0.9989 & $74.55 \pm 0.71 \mathrm{a}$ & $0.27 \pm 0.01$ \\
PM-WMS & $377.05 \pm 19.08$ & $0.13 \pm 0.00 \mathrm{a}$ & 0.9989 & $72.61 \pm 4.60 \mathrm{a}$ & $0.25 \pm 0.00$ \\
\hline
\end{tabular}

Mean values of two repetitions \pm standard deviation. Mean values marked with the same letter in the column do not significantly differ at significance level of 0.05

describing a given phenomenon. Figure 8 shows projection of ketchup samples thickened with modified starches on the plot of reduced factors. Factors 1 and 2 explain 59.06 and $14.90 \%$, respectively, of the variation in samples. On the basis of the distribution of the ketchup samples on the PCA plot, it can be stated that there were both similarities and differences in rheological properties of the samples. In the case of ketchups thickened with chemically modified starches, both the kind of starch modification and botanical origin of the starch significantly differentiated the compared ketchups in respect to their rheological properties. Ketchups thickened with acetylated distarch adipate starches showed significantly different rheological behaviors that resulted from different botanical origin of the modified starches. Samples with physically modified starches did not differ significantly in rheological behavior, despite various botanical sources of the starches. Rheological properties of ketchup thickened with HDP-WMS starch were similar to those demonstrated by ketchups thickened with physically modified starches.

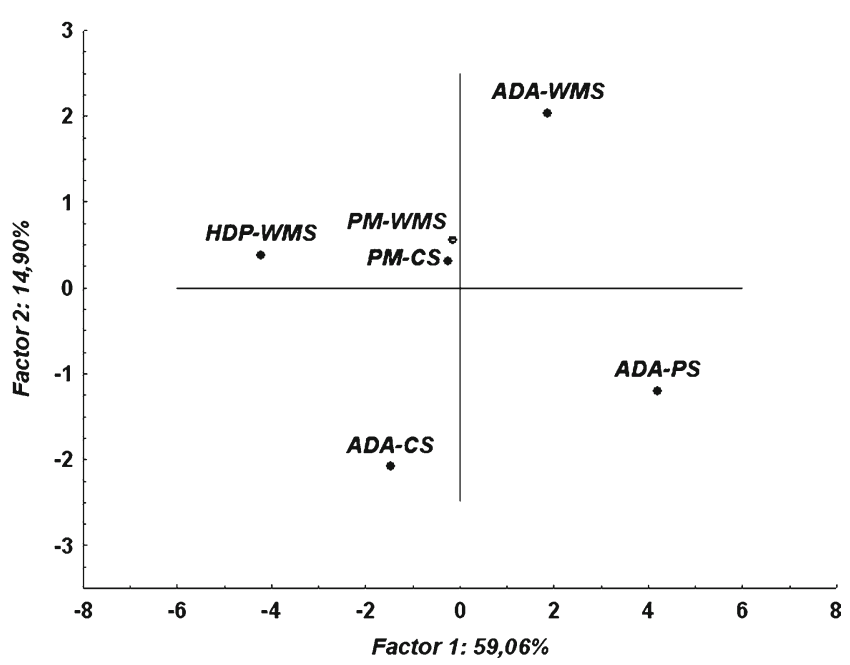

Fig. 8 Principal component analysis with distribution of ketchup samples thickened with modified starches

\section{Conclusions}

Ketchups produced with different starch thickeners show bimodal particle size distribution. The first maximum is connected with presence of swollen and partially gelatinized starch granules and it is determined by botanical origin of the starch. The second maximum results from presence of solid particles originating from tomato pulp. The particle size distribution derived from tomato pulp and starch is an essential factor that determines rheological properties of ketchup. The examined samples were characterized as rheologically unstable non-Newtonian, shear-thinning fluids with tendency to yield stress. Values of apparent viscosity of ketchup samples depended on the kind of starch thickener. A negative correlation between Bostwick consistency and selected rheological parameters of the flow curves was found. The susceptibility of ketchups to temperature treatment depended on the kind of modified starch used to thicken the samples. The mechanical spectra of ketchups showed that the samples were viscoelastic, with domination of elastic features. Ketchups thickened with physically modified starches showed rheological properties similar to each other, despite the differences in botanical origin of the starches. On the other hand, in the case of ketchups thickened with chemically modified starches, both kind of modification and botanical origin of the starch significantly differentiated the samples in respect to their rheological characteristics. Ketchups prepared with addition of acetylated distarch adipate differed in rheological properties between each other, suggesting that these differences resulted from various botanical origins of the starch modified by the same chemical method. In this case, the particle size distribution can be recognized as the main factor in determining rheological properties of ketchups. Ketchup thickened with HDP-WMS was similar in the rheological behavior to the ketchup samples with physically modified starches, which also could be used as a thickening agent in the ketchup production. 
Open Access This article is distributed under the terms of the Creative Commons Attribution License which permits any use, distribution, and reproduction in any medium, provided the original author(s) and the source are credited.

\section{References}

ASTM Standard F 1080-93 (2002) Standard test method for determination the consistency of viscous liquids using a consistometer. ASTM International.

Alvarez, E., Cancela, M. A., \& Maceiras, R. (2004). Comparison of rheological behavior of sweet and salad sauces. International Journal of Food Properties, 3, 511-518.

Barbana, C., \& El-Omri, A. (2009). Viscometric behavior of reconstitued tomato concentrate. Food and Bioprocess Technology. doi:10.1007/s11947-009-0270-3.

Basu, S., Shivhare, U. S., \& Raghavan, G. S. V. (2007). Time dependent rheological characteristics of pineapple jam. International Journal of Food Engineering, 3(3), article 1.

Bayod, E., Willers, E. P., \& Tornberg, E. (2008). Rheological and structural characterization of tomato paste and its influence on the quality of ketchup. LWT- Food Science and Technology, 41, 1289-1300.

Bottliglieri, P., De Sio, F., Fasanaro, G., Mojoli, G., Impembo, M., \& Castaldo, D. (1991). Rheological characterization of ketchup. Journal of Food Quality, 14, 497-512.

Choi, Y. H., \& Yoo, B. (2004). Characterization of time-dependent flow properties of food suspensions. International Journal of Food Science and Technology, 39, 801-805.

Farahnaky, A., Abbasi, A., Jamalian, J., \& Mesbahi, G. (2008). The use of tomato pulp powder as a thickening agent in the formulation of tomato ketchup. Journal of Texture Studies, 39, 169-182.

Galanakis, C. M., Tornberg, E., \& Gekas, V. (2010). Dietary fiber suspensions from olive mill wastewater as potential fat replacements in meatballs. LWT-Food Science and Technology, 43, 1018-1025.

Gibiński, M., Kowalski, S., Sady, M., Krawontka, J., Tomasik, P., \& Sikora, M. (2006). Thickening of sweet and sour sauces with various polysaccharide combinations. Journal of Food Engineering, 75, 407-414.

Gujral, H. S., Dharma, A., \& Singh, N. (2002). Effect of hydrocolloids, storage temperature and duration on the consistency of tomato ketchup. International Journal of Food Properties, 1, 179-191.

Juszczak, L., Witczak, M., Fortuna, T., \& Banyś, A. (2004). Rheological properties of commercial mustards. Journal of Food Engineering, 63, 209-217.

Koocheki, A., Ghandi, A., Razavi, S. M. A., Mortazavi, S. A., \& Vasiljevic, T. (2009). The rheological properties of ketchup as a function of different hydrocolloids and temperature. International Journal of Food Science and Technology, 44, 596-602.

Krokida, M. K., Maroulis, Z. B., \& Saravacos, G. D. (2001). Rheological properties of fluid fruit and vegetables puree products: compilation of literature data. International Journal of Food Properties, 2, 179-200.

Lee, Y. I., Lee, S. J., \& Noh, W. S. (1997). Effect of the modified starch on the physical properties of tomato ketchup. Agricultural Chemistry and Biotechnology, 1, 48-52.

Mazaheri Tehrani, M., \& Ghandi, A. (2007). Modification of Bostwick method to determine tomato concentrate consistency. Journal of Food Engineering, 79, 1483-1486.

McCarthy, K. L., Sacher, R. F., \& Garvey, T. C. (2008). Relationship between rheological behaviour and Bostwick measurement during manufacture of ketchup. Journal of Texture Studies, 39, 480-495.

Ochmańska, E. (2006). Raport: mokre przyprawy. Trendy Food, 2, 30 40.

Porretta, S. (1991). Analytical profiling of ketchup. Journal of the Science of Food and Agriculture, 57, 293-301.

Sahin, H., \& Özdemir, F. (2004). Effect of some hydrocolloids on the rheological properties of different formulated ketchups. Food Hydrocolloids, 18, 1015-1022.

Sahin, H., \& Özdemir, F. (2007). Effect of some hydrocolloids on the serum separation of different formulated ketchups. Journal of Food Engineering, 81, 437-446.

Sànchez, M. C., Valencia, C., Gallegos, C., Ciruelos, A., \& Latorre, A. (2002). Influence of processing on the rheological properties of tomato paste. Journal of the Science of Food and Agriculture, 82, 990-997.

Sharoba, A. M., Senge, B., El-mansy, H. A., Bahlol, H. E., \& Blochwitz, R. (2005). Chemical, sensory and rheological properties of some commercial German and Egyptian tomato ketchups. European Food Research and Technology, 220, 142-151.

Thakur, B. R., Singh, R. K., \& Handa, A. K. (1996). Effect of added soy protein on the quality of tomato sauce. Journal of Food Processing and Preservation, 20, 169-176.

Tharanathan, R. N. (2005). Starch-value addition by modification. Critical Reviews in Food Science and Nutrition, 45, 371-384.

Valencia, C., Sànchez, M. C., Ciruelos, A., Latorre, A., Franco, J. M., \& Gallegos, C. (2002). Linear viscoselasticity of tomato sauce products: influence of previous tomato paste processing. European Food Research and Technology, 214, 394-399.

Valencia, C., Sànchez, M. C., Ciruelos, A., \& Gallegos, C. (2004). Influence of tomato paste processing on the linear viscoelasticity of tomato ketchup. Food Science and Technology International, 10, 2, 95-100.

Varela, P., Gámbaro, A., Giménez, A. M., Durán, I., \& Lema, P. (2003). Sensory and instrumental texture measures on ketchup made with different thickeners. Journal of Texture Studies, 34, 317-330. 